home, although the facts are that the surreptitious freeing of one hand from the controllers was made the subject of heated controversy in 1924 and has been suggested many times since as the means whereby certain of the minor 'phenomena' were produced. Prof. Fraser-Harris concludes by the plea that these occurrences are worthy of scientific examination and that this demonstration of exteriorised energy opens up a new era in psychical research. He appreciates the difficulties both from the point of view of the physiologist and that of the physicist, but is of the opinion that the way is now open for the independent verification of the disputed phenomena. Certainly if the recent claims made by MM. Osty on behalf of the medium can be substantiated, then an important step forward has been made.

\section{Life-Saving Appliances on Merchant Ships}

THE Royal Society of Arts has several times given awards for inventions in connexion with life-boats and in 1878 it appointed a committee to consider marine life-saving apparatus. Its interest in nautical affairs is also shown by the Thomas Gray lectures, which were this year given by Capt. O. A. Barrand and Mr. G. A. Green on life-saving appliances on merchant ships, reports of which have now appeared (J. Roy. Soc. Arts, Sept. 16, 23, 30, Oct. 7). The lectures were divided into sections dealing with life-buoys and life-jackets, coastal life boats, ships' boats, boat stowage and buoyant apparatus. The credit for the design of the "Standard" life-jacket, we learn, belongs to certain officers of the Board of Trade, but jackets can be manufactured by anyone if permission is obtained. The best jackets are now of 'kapok', which when suitably packed has a buoyancy value of $3 \frac{1}{2}$ times that of cork. Kapok is the seed-hair of a plant growing in the East, but only Java kapok is permitted in life-jackets. The tests for jackets are stringent and the Standard jacket has to contain $24 \mathrm{oz}$. of the best Java kapok and to be capable of supporting $20 \mathrm{lb}$. of iron after floating in fresh water for 24 hours with $16 \frac{1}{2} \mathrm{lb}$. of iron attached. The loss of buoyancy of Java kapok has been shown to be only 10 per cent in thirty days' immersion.

\section{Annual Weather Report}

THF recently published annual volume of the Weekly Weather Report (London: H.M. Stationery Office) is the fifty-fourth annual summary of weather recorded at official weather stations or stations maintained by private individuals in co-operation with the Meteorological Office, in which the week is made the unit of time. Until recent years, summaries of individual weeks were printed within a short time after the conclusion of each week, but since that was discontinued, advantage has been taken of the opportunity thereby afforded of presenting a whole year's data in a form that should be extremely handy for the statistician who seeks to relate agricultural statistics of crops with the weather. The week has for long been held by many meteorologists to be the ideal unit of time in agricultural meteorology, and the Weekly Weather Report has always aimed at being the farmer's weather report. This explains why in this latest volume the period begins on March 1, 1931, afid ends on February 27, 1932, so as to cover a farmer's year. The main features of the weather of the whole year for any one of the twelve 'districts' into which the British Isles are divided are readily seen by the inspection of a few columns of figures, occupying only one-third of a page. Where the progress of events for a single place are of more interest, recourse has to be made to the weekly figures for the sixty individual representative stations, which are set out so that one page shows all the figures for one station only. In this particular volume the widespread incidence of abnormally cold and wet weather during the harvest period of 1931 over England is one of the most striking features; the general character of the phenomenon is shown by the weekly deviations of temperature and rainfall for English 'districts', and one can compare its severity at places so far apart as Durham and Jersey. The corresponding figures for Scotland and Ireland show the varying extent to which the northern parts of those countries escaped this visitation.

\section{Radium in Great Britain}

IN the Third Annual Report of the National Radium Trust and Radium Commission, 1931-1932 (H.M. Stationery Office. Price $9 d$. net), details are given of the purchases of radium by the Trust, and of the distribution of the supply by the Commission. We gather that the supply of national radium amounts to about $19 \mathrm{gm}$., excluding $4 \mathrm{gm}$. formerly comprising the 'bomb', now acquired by King Edward's Hospital Fund for London. The cost of this supply with the necessary containers has amounted to $£ 217,937$. It is noted that in spite of the stress laid by the Commission upon the necessity for the observance of the approved precautions for the safe custody of radium, avoidable losses have occurred at three of the national centres, which the Commission regards as resulting from breaches of the radium regulations. The reports deal only with administrative matters and no details of treatment are included.

\section{Seeding of Frog-bit in Great Britain}

Miss Gladys V. Hoare writes from the Royal Holloway Collega, Egham, Surrey, that plants of frog-bit (Hydrocharis Morsus-rance) under observation in the Botany Garden of the College have recently set seed. This is worthy of note since the plant usually reproduces itself vegetatively by means of turions, and reproduction by seed has not been reported for Britain by such well-known authorities as Sir Joseph Hooker and Mrs. Arber. In fact, it is frequently stated that the fruit is rare in Great Britain. Mr. Wilmott of the Natural History Museum showed Miss Hoare four seeds sent to him by Miss Corfe from Glastonbury in 1926. Miss Hoare suggests a connexion between this seedling and the special condition of the summer weather, and would be glad to know whether any other naturalist has collected seeds this year.

No. 3288, VoL. 130] 